\title{
Agência, affordance e a relação professor-materiais curriculares em Educação Matemática
}

\author{
Gilberto Januario ${ }^{1}$
}

\section{RESUMO}

A relação entre professores que ensinam Matemática e materiais curriculares é implicada por diferentes recursos e resultado do grau de agência e da percepção de affordances. Neste artigo, fazemos uma abordagem desses dois conceitos como marco conceitual de análise dos modos como professores e materiais curriculares se relacionam, tendo como referência resultados de estudos que vimos realizando no campo da Educação Matemática. A discussão aqui feita evidencia diferentes conceitos e noções incorporadas à interação entre professores e materiais curriculares, como fidelidade curricular; subversão curricular; contexto institucional; planejamento conjunto; professores como produtores de currículo; e descolonização do currículo. Essas noções, por sua vez, demandam propostas de investigação para a compreensão dos modos como influenciam a interação e potencializam o desenvolvimento curricular em Matemática.

PALAVRAS-CHAVE: Relação professor-materiais curriculares. Affordance. Agência. Educação Matemática.

Agency, affordance and the relationship teacher-curriculum materials in Mathematics Education

\begin{abstract}
The relationship between Math teachers and the curriculum materials is implied by different resources and the results of the agency rate and the perception of affordances. In this article, we build an approach of those two
\end{abstract}

\footnotetext{
${ }^{1}$ Doutor em Educação Matemática. Universidade Federal de Ouro Preto (UFOP), Ouro Preto, Minas Gerais, Brasil. https://orcid.org/0000-0003-0024-2096.januario@ufop.edu.br.
} 
concepts as a conceptual analysis mark about how teachers and curriculum materials interact, having as reference, results of studies we made in the Mathematics Education field. The discussion here shows different concepts and notions embodied with the interaction between teachers and curriculum materials, such as curriculum fidelity; curriculum subversion; institutional context; joint planning; teachers as curriculum producers and the curriculum descolonization. This notions, demand investigation proposals to comprehend the ways of how they influence the interaction and potentialize the curriculum development in Mathematics.

KEYWORDS: Relationship teacher-curriculum materals. Affordance. Agency. Mathematics Education.

Agencia, affordance y la relación profesor-materiales curriculares en Educación Matemática

\section{RESUMEN}

En la relación entre profesores que enseñan Matemática y materiales curriculares intervienen distintos recursos, condicionándola al grado de agencia y la percepción de affordances. En este artigo se aborda dichos conceptos como marco conceptual de análisis de los modos como profesores y materiales curriculares se relacionan, teniendo en cuenta los resultados de estudios que hemos desarrollado en el campo de la Educación Matemática. La discusión realizada pone de manifiesto distintos conceptos y nociones relativas a la interacción entre profesores y materiales curriculares, tales como fidelidad curricular; subverción curricular; contexto institucional; planificación conjunta; profesores como productores de currículo; y descolonización del currículo. Dichas nociones, a sua vez, requieren de propuestas de investigación para la compreensión de los modos como influencian la interacción y potencializan el desarrollo curricular en Matemática.

PALABRAS CLAVE: Relación profesor-materiales curriculares. Affordance. Agencia. Educación Matemática. 


\section{Abrindo a discussão}

Nas situações de aula de Matemática, professores e materiais curriculares trazem seus recursos para o desenvolvimento do currículo, implicando distintos modos de mediar/promover situações de aprendizagem, resultando em diferentes interações entre ambos os agentes.

Essa interação é implicada por distintas perspectivas teóricas do campo da Educação e da Educação Matemática, com interface em teorizações de diferenciadas áreas do saber. Nesse sentido, temos por objetivo a discussão de um marco conceitual para compreender fatores que podem balizar a relação entre os materiais curriculares e os professores, em especial, os conceitos de agênia e affordance. Essa discussão tem como referência estudos que vimos realizando sobre a relação professor-materiais curriculares no âmbito da Educação Matemática.

Como objetos de estudo, os currículos e seus níveis de desenvolvimento têm despertado nossa atenção por entendermos que diferentes aspectos dos processos de ensino e de aprendizagem, do desenvolvimento profissional docente e de políticas públicas da Educação estão implicados - e implicam nas teorizações e nas práticas dos currículos. Em relação a materiais curriculares, as experiências como formador de professores que ensinam Matemática e a problematização, com esses profissionais, de características dos recursos e de suas opções teóricas, didáticas e metodológicas nos motivaram a tomar a relação entre esses agentes como foco de investigação.

\section{Contextualizando o campo de pesquisa}

No Brasil houve diferentes iniciativas para munir as escolas públicas com livros didáticos e, assim, subsidiar professores e estudantes nos processos de ensino e de aprendizagem. Além de ações do governo federal, Estados e Municípios também produziram - e produzem - materiais para implementar suas propostas curriculares. 
Com a publicação de documentos, como os Parâmetros Curriculares Nacionais, na década de 1990, muitos materiais passaram a ser produzidos a partir das perspectivas teórica, didática e metodológica contidas neles. Como exemplo, citamos os materiais avaliados e entregues às escolas públicas no âmbito do Programa Nacional do Livro Didático.

Seja de programas federais ou de ações de estados ou municípios, um volume considerável de material curricular é disponibilizado a professores e estudantes para subsidiar os processos de ensino e de aprendizagem (JANUARIO e MANRIQUE, 2019). Como currículo apresentado (SACRISTÁN, 2000), esses materiais traduzem as prescrições oficiais nos modos de organizar e selecionar os conteúdos; de tratá-los sob abordagens conceitual, didática e metodológica; de estabelecer interfaces com materiais manipulativos e artefatos tecnológicos; e de apresentar sugestões de desenvolvimento curricular.

Talvez por isso, os materiais curriculares, especialmente livros didáticos e cadernos de atividades elaborados por Secretarias de Educação, são os principais recursos de que os professores lançam mão para planejar, realizar suas aulas e oportunizar processos de aprendizagens a seus estudantes (JANUARIO, 2018).

No entender de Lloyd, Remillard e Herbel-Eisenmann (2009), compreender a forma que os professores que ensinam Matemática se relacionam com materiais curriculares e os motivos de suas escolhas é importante para conhecer o trabalho docente face ao desenvolvimento curricular, as transformações dos materiais na prática pedagógica e o impacto para as aprendizagens dos estudantes.

Em relação ao contexto nacional brasileiro, um estudo realizado por nós mostrou um número de 59 trabalhos relacionados à área de Ensino de Ciências e Matemática e à área de Ensino em que esses recursos foram foco de investigação. Desse número, apenas duas pesquisas tiveram como objeto de estudo a relação entre professores e currículo (JANUARIO, PIRES e MANRIQUE, 2018). 
A relação professor-materiais curriculares tem sido objeto de investigação de alguns projetos de pesquisa, que têm contribuído com a discussão dessa temática a partir da produção de pesquisas, concluídas ou em fase de desenvolvimento. Como mostram Crisostomo, Januario e Lima (2017) e Martins, Curi e Santos (2019), os estudos concluídos têm diferentes abordagens ou estratégias metodológicas, entre pesquisas empíricas e teóricas, em que as coletas dos dados se deram por meio de observação de aulas; uso de entrevistas e questionários com professores; filmagem de aulas; e análise de documentos e materiais curriculares.

As análises dessas pesquisas tiveram como fundamentação os conceitos de recontextualização e de discurso pedagógico da teoria dos códigos de Basil Berstein, a discussão de crenças e concepções por Débora Ball e Lee Shulman e os estudos da relação professor-currículo de Janine Remillard, Matthew Brown e colaboradores. Como resultados das análises, os pesquisadores ponderam que: as atividades nem sempre são realizadas pelos professores conforme são propostas pelos elaboradores dos materiais; há diferentes tipos de relação de fidelidade aos materiais, como resistência a transformações, adaptação, improvisação e recontextualização; os professores interferem nos materiais para atender a seus princípios; o controle sobre o uso do material está centrado no professor e poucas vezes é partilhado com os estudantes; conhecimentos, crenças e concepções dos professores influenciam no modelo de ensino centralizador; e os professores reproduzem, adaptam e improvisam com os materiais em uma mesma aula, sendo que as improvisações, muitas vezes, vão de encontro às sugestões e opções didático-metodológicas dos materiais curriculares, resultando em práticas não propostas pelos elaboradores desses recursos.

Esses projetos e suas pesquisas sinalizam o interesse da comunidade acadêmica de Educação Matemática, no cenário nacional brasileiro, em investigar e produzir conhecimentos sobre a relação professor-materiais curriculares e em compreender fatores que influenciam essa relação e seus efeitos para os processos de desenvolvimento profissional, de ensino e de 
aprendizagem da Matemática e para as políticas públicas da Educação. Sinalizam, ainda, a origem de um campo de investigação que toma os professores, os materiais curriculares e a interação entre ambos como interesse de estudo e de proposição de teorizações para o desenvolvimento curricular.

\section{Explorando os conceitos de agência e affordance}

Materiais curriculares podem configurar-se em região de inquérito da pesquisa brasileira articulados ao desenvolvimento profissional docente, especialmente no que se refere à formação inicial e continuada de professores que ensinarão/ensinam Matemática. A Formação de Professores, como linha de pesquisa consolidada em Educação Matemática, pode incorporar pesquisas sobre currículos e materiais curriculares tomando esses recursos como objetos que contribuem para: a aprendizagem matemática dos professores; a iniciação à docência; a constituição da identidade profissional; a (re)construção de concepções, crenças e valores da Matemática, do desenvolvimento curricular e do percurso de aprendizagem dos estudantes; e a prática dos professores como produtores de cultura e de currículo.

Nesse sentido, Currículos de Matemática, como linha de pesquisa, pode incorporar a formação de professores tomando suas diferentes temáticas como fatores que implicam e são implicados pelas teorizações sobre currículos, pela política de elaboração, avaliação e distribuição de materiais curriculares, pelas características dos materiais e dos professores e pela relação professormateriais curriculares.

O estudo dessa relação implica a concepção de que professores e materiais curriculares são agentes ativos e ambos apresentam seus recursos (BROWN, 2002, 2009) que delimitam o desenvolvimento curricular. Professores e materiais têm características que imprimem poder de decisão e de escolha sobre o currículo e particularmente os materiais apresentam elementos que informam as possibilidades de uso para que os propósitos do 
processo formativo sejam contemplados. Assim, da análise da interação entre professores e materiais curriculares apreendemos as noções de agência e affordance.

Em materiais curriculares de Matemática há diferentes aspectos e propriedades que são percebidas pelos professores ou pelos estudantes. Esses elementos atuam como informações demandadas pelo material, que ao serem captadas, comunicam as possibilidades de ação com ele. As possibilidades de ação de um objeto, inferidas por um agente externo a ele, são chamadas de affordance (GIBSON, 1966).

Em relação aos materiais curriculares usados por professores ao mediar/promover situações de aprendizagem, diferentes informações podem ser captadas e, do ponto de vista desses profissionais, possibilitam o desenvolvimento curricular potencializando e qualificando os processos de ensino e de aprendizagem. Assim, as affordances inferidas pelos professores podem ser entendidas como: a articulação entre diferentes expectativas e objetivos; a interface com artefatos tecnológicos; a articulação com outros materiais curriculares; a explicitação de aspectos conceituais, didáticos e metodológicos das atividades; o engajamento no desenvolvimento curricular; a conexão entre novos conceitos e práticas sociais dos estudantes (aprendizagem significativa); o engajamento dos estudantes; a interdisciplinaridade; a manifestação, pelos estudantes, de seus saberes; a elaboração, testagem e validação de hipóteses e as interações sociais; a promoção dos conceitos; o tratamento de questões envolvendo família, lugares e animais; a elaboração, pelos estudantes, de argumentos e justificativas, de perguntas; o trabalho em equipe; o desenvolvimento de competências leitora e escritora; o desenvolvimento da autonomia, do protagonismo e da autoria nos estudantes.

O que destacamos como affordances são as possibilidades de uso dos materiais curriculares inferidas pelos professores. Isso não significa que elas estão explícitas ou anunciadas nos materiais em forma de orientações e atividades, mas que são fruto da percepção dos professores sobre as 
informações, características e propriedades que os materiais demandam.

A partir do que teorizou Gibson (1977, 1986), compreendemos que os elementos que os materiais demandam conectam percepção e aspectos cognitivos dos professores ao uso desses recursos. Assim, as affordances inferidas são fruto de ações cognitivas desses profissionais que se relacionam diretamente com os materiais curriculares. As affordances, como oportunidades de ação para os processos de ensino e de aprendizagem, são dos materiais e estão neles, independentemente de serem inferidas ou não.

Essa inferência, como ação cognitiva, é balizada pelos conhecimentos, crenças e valores dos professores sobre a Matemática, seu ensino, os próprios materiais curriculares e sobre o percurso formativo dos estudantes. São os recursos dos professores, como explicitou Brown (2002, 2009), que permitem maior ou menor inferência de affordances nos materiais curriculares. As affordances, então, embora sejam dos materiais, dependem dos recursos dos professores para serem inferidas.

A depender de seus conhecimentos, crenças e valores, os professores podem explorar em maior ou menor grau as affordances de um material curricular, o que implicará em diferentes modos de interação professorcurrículo. Assim, o uso de materiais curriculares pelos professores, ao mediar/promover situações de aprendizagem, é balizado pelo grau de affordances inferidas, no que se refere: às intervenções em relação à organização e seleção dos conteúdos; à sequenciação das atividades; à exploração de opções didáticas e metodológicas; ao tratamento de aspectos conceituais; ao encaminhamento de exploração, investigação e sistematização de conceitos e estratégias pelos estudantes; ao desenvolvimento de competências escritora, leitora e autoral dos estudantes; e ao uso de outros recursos e artefatos para complementar as atividades propostas no material curricular, por exemplo, livros, jogos, revistas, jornais, sites de internet, aplicativos, objetos de aprendizagem.

As intervenções feitas pelos professores têm como propósito atender às suas expectativas em relação ao desenvolvimento curricular, ao que foi 
planejado em consonância com o Projeto Político Pedagógico da escola e às demandas dos estudantes referentes aos processos de ensino e de aprendizagem da Matemática. Desse modo, como ponderou Gibson (1986) sobre a relação objeto-ambiente-sujeito de um ecossistema, os materiais curriculares e os professores estão vulneráveis a mudanças de diferentes ordens, dentre elas o cotidiano escolar e o ambiente de aula.

O grau de affordances inferidas de um material curricular, em maior ou menor grau, provoca nesses recursos o poder de decisão sobre o currículo ou confere esse poder aos professores. A autoridade sobre as decisões curriculares está associada à noção de agência.

Como capacidade de tomada de decisão de um sujeito ou objeto nas relações situadas em um contexto social (GIDDENS, 1989), a agência é a forma pela qual materiais curriculares ou professores exercem poder sobre a Matemática e seu ensino, transformando sentidos e significados das atividades e implicando os processos de ensino e de aprendizagem, como podemos observar na Figura 1.

Figura 1: Professores, materiais, seus recursos e a relação professormateriais curriculares

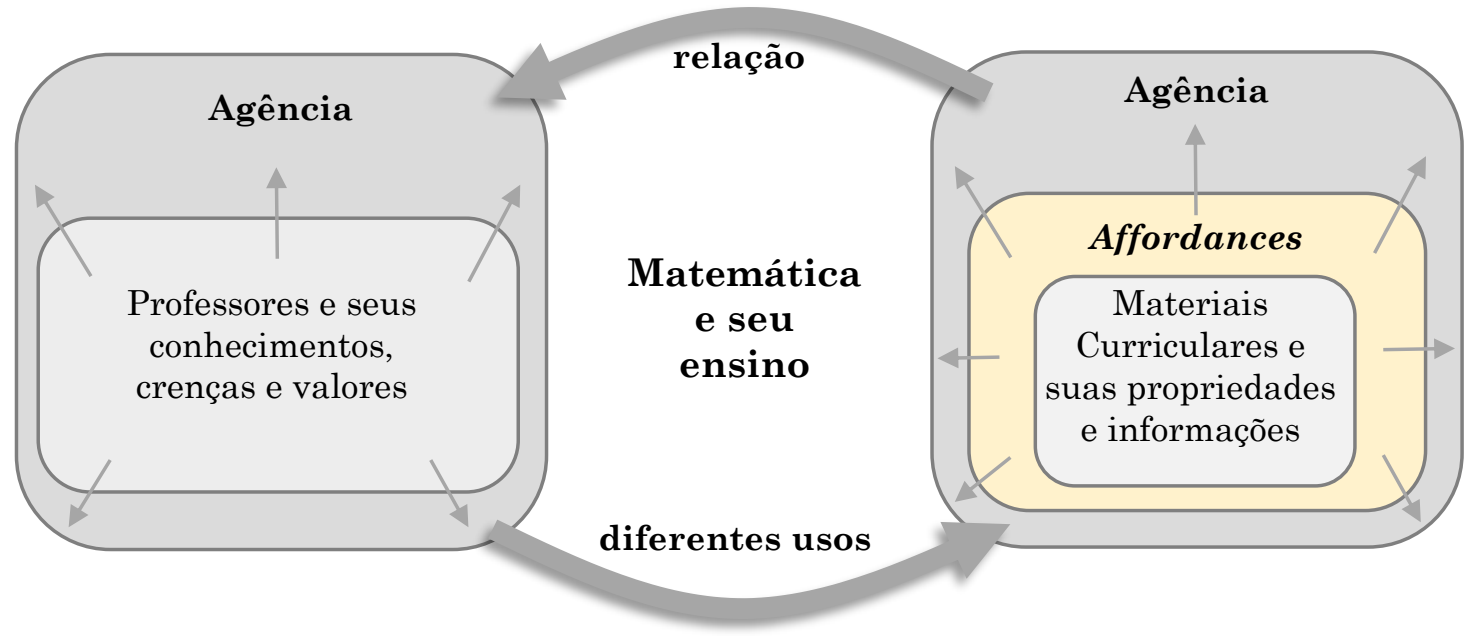

Fonte: Elaboração do Autor

Como agentes do desenvolvimento curricular, professores atuam de 
modos distintos sobre suas escolhas, movidos por seus conhecimentos, crenças e valores da Matemática, dos materiais curriculares e do percurso de aprendizagem dos estudantes. Esses elementos que induzem graus distintos de agência são chamados de estrutura (GIDDENS, 1989, 2001, 2010). Em relação aos materiais curriculares, os diferenciados graus de agência são delimitados por informações captadas pelos professores e pela inferência de affordances. Assim, conforme o grau de affordance, o material curricular apresenta maior ou menor capacidade de agência.

$\mathrm{Na}$ relação professor-materiais curriculares, affordance e agência são conceitos centrais que possibilitam elementos para a análise do uso desses recursos, de características que incutem poder nos materiais e de elementos que conferem autoridade ao professor, como ilustra a Figura 1.

Entendemos que a capacidade de percepção de informações nos materiais curriculares e a inferência de affordances pelos professores são possibilitadas pelo conhecimento da Matemática; dos aspectos conceituais, didáticos e metodológicos referentes ao seu ensino; do desenvolvimento curricular. São possibilitadas também pelo conhecimento que esses profissionais adquirem a partir da experiência ao mediar/promover situações de aprendizagem; pelas hipóteses que têm sobre as necessidades de aprendizagem dos estudantes; e pela concepção de educação e de prática formativa em Matemática.

Como podemos observar na Figura 1, a inferência de affordances implica os materiais curriculares como agência, que exercem sobre o desenvolvimento curricular autoridade sobre a Matemática e seu ensino. Como agência, os materiais são percebidos pelos professores como recursos com qualidades e possibilidades para materializar as expectativas, ou objetivos, em forma de atividades e, assim, promover e potencializar as aprendizagens dos estudantes. A agência nos materiais leva os professores a ter fidelidade sobre esses recursos e a seguir ou reproduzir o currículo (BROWN, 2002, 2009; REMILLARD, 2005). Como agência, os materiais curriculares atuam enquanto indutores do currículo e delimitam a proposta e 
a experiência de formação matemática dos estudantes.

Ao captar informações nos materiais curriculares que impõem restrições a esses recursos, os professores assumem para si a autoridade sobre a Matemática e seu ensino. Como agência, esses profissionais identificam fragilidades e subvertem o currículo (REMILLARD, 2005), adaptando sequências de atividades ou improvisando em situações de aulas (BROWN, 2009). Os professores, como agentes, intervêm nos materiais curriculares para atender aos seus propósitos e desenvolvem o currículo fundamentados em seus conhecimentos, crenças e valores.

A análise de um relatório de pesquisa realizado por nós (JANUARIO e MANRIQUE, 2019) mostrou que, como agentes, professores e materiais curriculares, ambos com seus recursos (BROWN, 2002), situados em um contexto de relações sociais, apresentam características que imprimem o poder de escolha e decisão sobre os processos de ensino e de aprendizagem. Nesse sentido, em decorrência da estrutura do contexto social (GIDDENS, 1989), ocorre o deslocamento de agência, ora para o professor, ora para os materiais curriculares.

Embora affordance e agência sejam qualidades e competências do material curricular, suas inferências dependem dos professores, ao se relacionar com o currículo. Disso, implica considerarmos que esses profissionais exercem autoridade sobre a quem delega o poder de ação no desenvolvimento curricular, pois são eles que decidem, a partir das affordances, o papel dos materiais curriculares na relação que exercem com eles.

No entanto, do que teoriza Giddens (1989), essas decisões docentes, embora sejam conscientes, suas consequências nem sempre são analisadas pelos professores. Agência, como autoridade sobre a Matemática e seu ensino, não é sinônimo de qualidade e pode implicar em resultados de aprendizagem que vão de encontro aos objetivos propostos para o processo formativo dos estudantes. Por isso, o processo de formação para o professor deve ser constante e possibilitar a análise de documentos e materiais curriculares, o 
estudo da Matemática e de diferentes teorizações da Educação Matemática e áreas correlatas e a reflexão sobre questões da contemporaneidade e as necessidades de aprendizagens dos estudantes.

Nesse sentido, embora affordance e agência estejam relacionadas às competências dos indivíduos em suas singularidades, práticas de formação conjunta com os pares possibilitam o debate, a reflexão, a troca de conhecimentos e a socialização de experiências que demandam os modos de ver e conceber os materiais curriculares e de se situar na relação com esses recursos, implicando na inferência coletiva de affordances e agência para si e para os materiais.

\section{Discutindo a relação professor-materiais curriculares à luz dos conceitos de agência e affordance}

As affordances, como possibilidades de uso, não podem ser traduzidas como propriedades que os materiais curriculares apresentam, ou nos princípios de seus elaboradores, ou em sua estrutura física, conceitual. Tratam-se do produto das informações disponíveis nos materiais, que precisam ser captadas pelo agente cognoscente, e da inferência pelos agentes que exploram esses recursos.

Como processo cognitivo associado ao que comunicam os materiais, a inferência de affordances é um ato do sujeito, do professor. Assim, cada profissional, ao se relacionar com materiais curriculares, capta diferentes informações e percebe "suas" affordances, ou seja, explora de um modo particular as possibilidades de uso dos recursos para atender aos propósitos referentes às aprendizagens dos estudantes.

Diferentes sujeitos percebem distintas affordances. Isso implica afirmar que os materiais curriculares assumem significados diferentes para cada professor que se relaciona com eles, uma vez que cada profissional atribui sentidos e significados aos materiais a partir de seus conhecimentos, crenças e valores da Matemática, de seu ensino, dos currículos e do processo 
formativo dos estudantes.

Entendemos conhecimentos, crenças e valores como o processo da experiência na formação inicial, na formação continuada, na formação em serviço e nos espaços de discussão e reflexão sobre a práxis docente e o desenvolvimento curricular. A essa tríade podemos associar os conhecimentos advindos da prática pedagógica, como: as hipóteses sobre as hipóteses dos estudantes; a experiência da gestão de tempos e espaços; os saberes sobre o percurso de vida dos estudantes; as expectativas e os desafios dos estudantes; a realidade do cotidiano escolar; e os modos como as políticas públicas afetam o cotidiano do trabalho pedagógico.

Esses conhecimentos, crenças e valores, enquanto recursos dos professores (BROWN, 2002, 2009) norteiam, assim, a inferência das affordances. Como consequência da exploração de possibilidades para a ação pedagógica, marcada por um contexto social de situação de aula, os materiais curriculares se configuram como agência e detém a autoridade sobre a Matemática e seu ensino.

Conceber materiais curriculares como agência resulta significá-los como recursos que melhor traduzem as prescrições em situações de aprendizagem e melhor apresentam e tratam os conceitos matemáticos em forma de atividades. Implica, assim, em práticas pedagógicas de fidelidade sobre o currículo apresentado e em usos como reprodução, em que os professores transferem para os recursos suas autonomias e seus conhecimentos, configurando o deslocamento de agência.

Os estudos que vimos realizando mostram os professores que ensinam Matemática como sujeitos que incutem, em maior ou menor grau, suas escolhas no desenvolvimento curricular, configurando uma não neutralidade nos modos de ver, conceber e agir com os materiais curriculares.

A competência participativa dos professores sobre as decisões curriculares é estimulada por seus conhecimentos, crenças e valores. Esses elementos estimulam nos professores a autonomia sobre a Matemática e seu ensino e caracterizam, assim, esses profissionais como agência. 
Conceber professores que ensinam Matemática como agência envolve a perspectiva de que esses profissionais são sujeitos que mobilizam seus mecanismos para atender aos objetivos dos processos de ensino e de aprendizagem, traduzindo orientações e sugestões contidas nos documentos ou nos materiais curriculares, personalizando os modos de apresentar e tratar os conceitos e conteúdos, fazendo uso e significando os materiais conforme suas concepções e suas intenções e intervindo nos materiais movidos por suas hipóteses e experiências da gestão de situações de aula.

Materiais curriculares, como objetos situados em um contexto social, podem apresentar restrições nos modos de propor orientações aos professores, de apresentar e tratar os conceitos matemáticos, de estabelecer interfaces com opções didático-metodológicas e teorizações da Educação Matemática e áreas correlatas. Como agência, os professores percebem essas restrições e atribuem sentidos e significados de fragilidades aos materiais, assumindo a agência do desenvolvimento curricular (deslocamento de agência).

O deslocamento de agência para os professores impulsiona a práticas de subversão sobre os materiais curriculares, resultando na fragilização da fidelidade sobre o currículo e em usos desses recursos como atividades de adaptação e improvisação.

É importante considerar que as restrições, possíveis de serem inferidas pelos professores, não se limitam a características dos materiais curriculares. Podem se referir a aspectos dos professores, como conhecimentos sobre a Matemática, as opções didáticas e metodológicas de seu ensino, aos materiais curriculares, ao desenvolvimento curricular e ao percurso formativo dos estudantes. Nesse caso, por serem sujeitos passíveis de limitação do ponto de vista de suas competências profissionais, os professores transferem sua autoridade para os materiais curriculares e transferem a responsabilidade do desenvolvimento curricular (deslocamento de agência).

As condições do contexto institucional também podem apresentar restrições ao desenvolvimento curricular e, assim, implicam a forma como os professores veem e concebem os materiais curriculares e a relação professor- 
currículo. Como exemplo, podemos citar: os modos como os materiais são concebidos e elaborados, se com ou sem a participação dos professores, o que resulta no processo de reconhecimento de suas concepções, do sentimento de pertença e da relação de fidelidade; o tempo de ensino, geralmente demarcado por períodos curtos como semanas ou bimestres, e o tempo de aprendizagem, que a depender do grau de complexidade dos conceitos e atividades e das dificuldades dos estudantes são incompatíveis com os tempos disponíveis; a forma de entrega e acompanhamento do uso dos materiais, se ocorre com ou sem formação para os professores, na qual se podem explicitar propósitos e concepções subjacentes; as condições de trabalho e a falta de tempos e espaços para a análise e a recontextualização do material e a discussão conjunta com os pares.

Em relação à formação continuada ou à participação em grupo de estudou em projeto de pesquisa, como possibilidade do encontro com os pares, permite aos professores conhecer dificuldades e experiências de seus colegas, além de compartilhar as suas. Nesse encontro, os professores verbalizam seus conhecimentos, crenças e valores e debatem sobre informações e propriedades dos materiais, expõem as affordances inferidas por eles e reconhecem a agência, ora em si, ora nos materiais curriculares. Essa dinâmica de participação oportuniza a cada professor ter acesso às affordances inferidas por seus pares e, como consequência, explorar possibilidades de uso dos materiais não inferidas no planejamento individual; oportuniza, ainda, o seu autorreconhecimento como sujeito de autoridade sobre o desenvolvimento curricular, a partir dos conhecimentos advindos de sua experiência de vida e trajetória profissional, deslocando a agência para si.

A análise do material curricular e o planejamento conjunto de seu uso oportunizam aos professores a percepção comum de propriedades e informações do material e a inferência de affordances, o que pode fazer com que cada professor se sinta mais confiante para realizar as atividades, assumindo a postura de sujeito autônomo e com controle sobre as escolhas e decisões do desenvolvimento curricular. Nesse caso, consideramos 
affordances e agência como conceitos que podem ser construídos na coletividade, a depender do envolvimento promovido pela formação.

Embora tenhamos assumido que conhecimentos, crenças e valores norteiam a inferência de affordances e o deslocamento de agência, estudos realizados por nós (JANUARIO, MANRIQUE e PIRES, 2018; JANUARIO e MANRIQUE, 2019) mostram que, ao analisar o material e planejar as aulas no grupo, com seus pares, os professores (re)constroem conhecimentos, crenças e valores da Matemática, do seu ensino, dos currículos e do processo formativo dos estudantes; reconhecem suas limitações e as potencialidades dos materiais curriculares ou reconhecem as fragilidades desses materiais e suas competências como profissionais; e recontextualizam o desenvolvimento curricular. Por isso, entendemos não ser suficiente aos professores ter acesso a materiais curriculares. É preciso investir em formação, continuada e em serviço, que garanta estratégias metodológicas para o engajamento dos professores em atividades conjuntas de avaliação dos materiais e do planejamento das atividades e para a análise da aula realizada.

Entendemos, ainda, que os professores que ensinam Matemática exercem o poder de escolha e de decisão sobre os materiais curriculares, ou fragmentos deles, a partir de fragilidades inferidas por meio da captação de propriedades e informações dos recursos. Como agência, os professores mobilizam conhecimentos provenientes de suas práticas, suas hipóteses e necessidades demandadas por seus estudantes, e analisam diferentes recursos para criar seus materiais curriculares em forma de sequências de atividades.

A competência para elaborar seus próprios materiais caracteriza o professor como produtor de currículo. Essa criação, como já mencionamos, envolve não apenas seus conhecimentos, mas também suas crenças e valores da Matemática, do ensino, dos currículos e do processo formativo dos estudantes. Conhecimentos, crenças e valores que fundamentam a prática de subversão dos professores em relação aos currículos elaborados, geralmente, por uma instância exterior à realidade escolar. Por isso, tendo como norte os 
objetivos para o ensino, as demandas formativas de seus estudantes e o conhecimento da trajetória de vida deles, os professores criam sequências de atividades que, do seu ponto de vista, possibilitam um processo melhor de ensino e de aprendizagem, em comparação com os materiais curriculares disponibilizados a eles, pois apresentam características que esses recursos não expõem, como a articulação entre o contexto social ao qual os estudantes estão inseridos e a realidade escolar.

A produção de currículos por professores — sequências de atividades - pode resultar no reconhecimento, sistematização e problematização de diferentes modos de pensar e agir matematicamente no contexto social no qual os estudantes se inserem, caracterizando o que chamamos de descolonização do currículo.

Descolonizar o currículo, nesse sentido, significa tomar as Matemáticas reveladas pelos estudantes em suas práticas sociais como ponto de partida para a construção de sentidos e significados de diferentes temas de interesse que possam emergir ao mediar/promover situações de aprendizagem. Significa, ainda, desconstruir uma única forma de ver e conceber a Matemática, cientificamente erigida pela perspectiva de seus elaboradores; reconhecer e respeitar as diferentes formas de pensar e agir matematicamente; admitir diferentes modos de produzir Matemática como meio de ser e estar no mundo; e compreender que a Matemática é produto de distintas atividades realizadas por grupos sociais e culturais diversos.

Em relação ao objetivo proposto para este artigo, nossa concepção de marco conceitual reporta-se a um conjunto de conceitos inter-relacionados, fundamentados em teorizações das ciências da Educação, da Educação Matemática e de áreas correlatas, que orientam a práxis do desenvolvimento curricular e contribuem para a construção de sentidos, interpretações e significados sobre a relação professor-materiais curriculares, ou professorcurrículo, ou professor-currículos. Diante do exposto, implica considerarmos que às noções de affordances e de agência, como marco conceitual, associamse diferentes conceitos, como já discutimos até aqui e conforme podemos 
observar na Figura 2: conhecimentos, crenças e valores; fidelidade curricular; subversão curricular; contexto institucional; planejamento conjunto; professores como produtores de currículo; e descolonização do currículo.

Figura 2: Marco conceitual para orientar a análise da relação professormateriais curriculares de Matemática

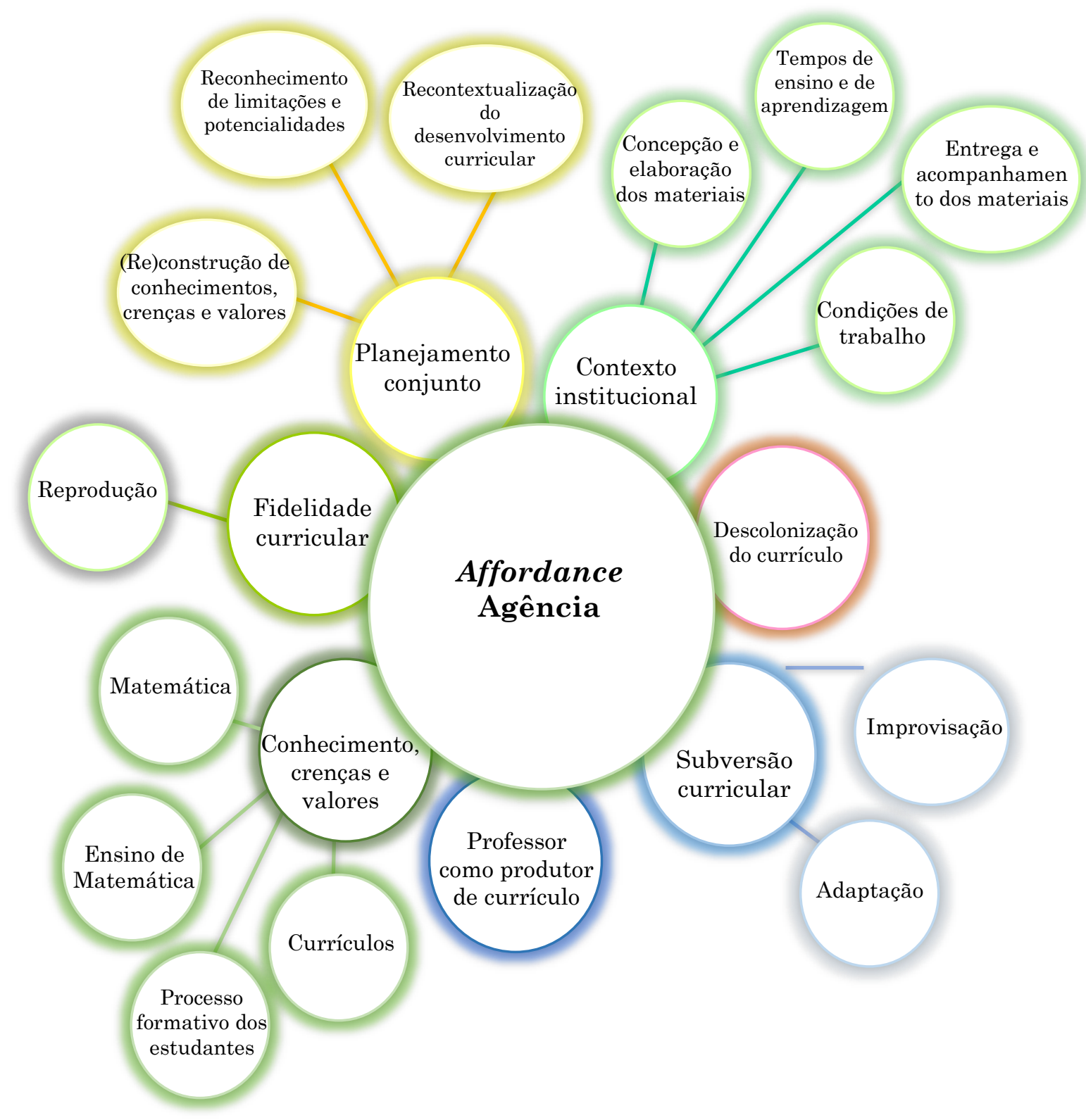

Fonte: Elaboração do Autor

A Figura 2 mostra como os conceitos de affordance e de agência, ideias centrais para compreender a análise da relação professor-materiais 
curriculares, estão associados a outras noções que, por sua vez, facilitam a compreensão dos sentidos e significados relativos a ambos.

Quanto ao marco conceitual aqui elaborado por nós, este emergiu do processo de nossa aproximação com teorizações dos campos da Educação, Educação Matemática, Sociologia e Psicologia. Trata-se de um modelo conceitual que pode ser tomado como referencial teórico para compreender a interação entre professores e materiais curriculares e, a esse marco, podem ser incorporados outros conceitos.

Por fim, explicitamos que os conceitos de affordance e agência discutidos não denotam juízo de valor. Na verdade, denotam a identificação de que os materiais curriculares possuem possibilidades para sua exploração, por professores e/ou estudantes, e que professores e materiais agem, em maior ou menor grau, com autoridade sobre o desenvolvimento curricular.

\section{Considerações}

No Brasil, a relação professor-materiais curriculares é um campo em potencial de formação no âmbito da linha Currículos de Matemática, na área de Educação Matemática. Esse aspecto requer discussões e pesquisas que tomem diferentes materiais curriculares, a práxis docente e a relação professor-currículo como objetos de investigação para a produção de conhecimentos.

A observação do marco conceitual discutido por nós evidencia diferentes conceitos, relacionados à interação entre professores e materiais curriculares, que demandam propostas de investigação para a compreensão dos modos como essas noções influenciam a interação e potencializam o desenvolvimento curricular.

Nesse sentido, é preciso o engajamento na proposição de projetos de pesquisa que tenham como objetivo a articulação da Formação de Professores com Currículos de Matemática, como campos consolidados na Educação Matemática, bem como a interface de outras linhas de pesquisa com os 
estudos no campo dos currículos, em que se tomem diferentes objetos de estudos: (a) os modos como os professores mobilizam seus recursos para interagir com os materiais; (b) a aprendizagem e o desenvolvimento profissional docente no relacionamento com os materiais; (c) as influências sobre os materiais curriculares quando de sua elaboração; (d) as implicações dos materiais para diferentes aspectos do processo educacional; (e) os materiais curriculares e suas influências para políticas públicas para a Educação; (f) o processo de descolonização do currículo a partir dos materiais; (g) o papel dos materiais no processo de produção de currículos pelos professores; (h) os conhecimentos, crenças e valores mobilizados pelos estudantes ao se relacionar com os materiais curriculares; (i) o contexto institucional e sua relação com a agência nos professores e nos materiais; e (j) as affordances e agência como demandas formativas.

Como formador de professores e pesquisador em Educação Matemática, na linha Currículos de Matemática, tomamos como responsabilidade a análise de materiais curriculares, a problematização de affordances e agência, a discussão da relação professor-materiais curriculares, a descolonização do currículo e a constituição do professor como produtor de currículos como temas que devem configurar a nossa atuação e trajetória acadêmica.

Em relação à pesquisa, esses temas, associados a outros que possam emergir do processo de formação e de investigação, têm delimitado nosso estudo sistemático sobre currículos e processos de desenvolvimento profissional docente a partir de suas relações com os diferentes níveis do currículo.

\section{Referências}

BROWN, M. W. Teaching by design: understanding the interaction between teacher practice and the design of curricular innovations. 2002, 543f. Tese (Doutorado em Ciências da Aprendizagem) - School of Education \& Social Policy, Northwestern University. Evanston, Illinois (EUA).

BROWN, M. W. The Teacher-Tool Relationship: theorizing the design and use of curriculum materials. In: REMILLARD, J. T; HERBEL-EISENMANN, B. A.; 
LLOYD, G. M. (Ed.). Mathematics Teachers at Work: connecting curriculum materials and classroom instruction. New York: Taylor \& Francis, 2009, p. 17-36.

CRISOSTOMO, E.; JANUARIO, G.; LIMA, K. Relação professor-materiais curriculares em Educação Matemática: análise de alguns resultados de pesquisas. Educação Matemática em Revista, Brasília, v. 22, n. 53, p. 62-74, jan./mar. 2017.

GIBSON, J. J. The ecological approach to visual perception. New Jersey: Lawrence Erlbaum Associates, 1986.

GIBSON, J. J. The senses considered as perceptual systems. Boston: Houghton Mifflin, 1966.

GIBSON, J. J. The theory of affordance. In: SHAW, Robert; BRANSFORD, John. (Ed.). Perceiving, acting, and knowing: toward an Ecological Psychology. New Jersey: Lawrence Erlbaum, 1977, p. 67-82.

GIDDENS, A. A constituição da sociedade. Tradução de Álvaro Cabral. São Paulo: Martins Fontes, 1989.

GIDDENS, A. A política da mudança climática. Tradução de Vera Ribeiro. Rio de Janeiro: Jorge Zahar, 2010.

GIDDENS, A. Em defesa da Sociologia: ensaios, interpretações e tréplicas. Tradução de Silvana Vieira e Roneide Venancio Majer. São Paulo: Edunesp, 2001.

JANUARIO, G,; PIRES, C. M. C.; MANRIQUE, A. N. Pesquisas sobre materiais curriculares de Matemática: mapeamento de produções brasileiras. Revista Electrónica de Investigación en Educación en Ciencias, v. 13, n. 1, p. 43-61, jul. 2018.

JANUARIO, G. Investigações sobre livros didáticos de Matemática: uma análise de suas questões de pesquisa. Educação, Escola \& Sociedade, Montes Claros, v. 11, n. 12 , p. $1-12$, jan./jun. 2018.

JANUARIO, G.; MANRIQUE, A. N. Teachers' interactions with curriculum materials in Mathematics Education. Acta Scientiae, Canoas, v. 21, n. 3, p. 2-23, jul./ago. 2019.

JANUARIO, G.; MANRIQUE, A. N.; PIRES, C. M. C. Conceitos de affordance e de agência na relação professor-materiais curriculares em Educação Matemática. Bolema, Rio Claro, v. 32, n. 60, p.1-30, jan./abr. 2018.

LLOYD, G. M; REMILLARD, J. T.; HERBEL-EISENMANN, B. A. Teachers' Use of Curriculum Materials: an emerging field. In: REMILLARD, J. T.; HERBELEISENMANN, B. A.; LLOYD, G. M. (Ed.). Mathematics teachers at work: connecting curriculum materials and classroom instruction. New York: Taylor \& Francis, 2009, p. 3-14.

MARTINS, P. B.; CURI, E.; SANTOS, C. A. B. O estado do conhecimento sobre as pesquisas brasileiras que focalizam as relações estabelecidas entre professores da educação básica com os materiais curriculares de Matemática. Educação Matemática Pesquisa, São Paulo, v. 21, n, 1, p. 461-176, jan./abr. 2019. 
REMILLARD, J. T. Examining key concepts in research on teachers'use of Mathematics Curricula. Review of Educational Research, Washington, American Educational Research Association, v. 75, n. 2, p. 211-246, jun. 2005.

SACRISTÁN, J. G. O currículo: uma reflexão sobre a prática. 3. ed. Tradução: Ernani F. da Fonseca Rosa. Porto Alegre: Artmed, 2000.

Recebido em janeiro de 2020.

Aprovado em março de 2020. 